University of Nebraska - Lincoln

DigitalCommons@University of Nebraska - Lincoln

$7-2004$

\title{
Monitoring Maize (Zea mays L.) Phenology with Remote Sensing
}

Andrés Viña

Michigan State University, vina@msu.edu

Anatoly A. Gitelson

University of Nebraska - Lincoln, agitelson2@unl.edu

Donald C. Rundquist

University of Nebraska - Lincoln, drundquist1@unl.edu

Galina P. Keydan

University of Nebraska - Lincoln, gkeydan2@unl.edu

Bryan Leavitt

University of Nebraska-Lincoln, bleavitt4@unl.edu

See next page for additional authors

Follow this and additional works at: https://digitalcommons.unl.edu/natrespapers

Part of the Natural Resources and Conservation Commons

Viña, Andrés; Gitelson, Anatoly A.; Rundquist, Donald C.; Keydan, Galina P.; Leavitt, Bryan; and Schepers, James, "Monitoring Maize (Zea mays L.) Phenology with Remote Sensing" (2004). Papers in Natural Resources. 264.

https://digitalcommons.unl.edu/natrespapers/264

This Article is brought to you for free and open access by the Natural Resources, School of at DigitalCommons@University of Nebraska - Lincoln. It has been accepted for inclusion in Papers in Natural Resources by an authorized administrator of DigitalCommons@University of Nebraska - Lincoln. 


\section{Authors}

Andrés Viña, Anatoly A. Gitelson, Donald C. Rundquist, Galina P. Keydan, Bryan Leavitt, and James Schepers 


\title{
REMOTE SENSING
}

\section{Monitoring Maize (Zea mays L.) Phenology with Remote Sensing}

\author{
Andrés Viña,* Anatoly A. Gitelson, Donald C. Rundquist, Galina Keydan, Bryan Leavitt, and James Schepers
}

\begin{abstract}
Monitoring crop phenology is required for understanding intraand interannual variations of agroecosystems, as well as for improving yield prediction models. The objective of this paper is to remotely evaluate the phenological development of maize (Zea mays $L_{\text {.) }}$ in terms of both biomass accumulation and reproductive organ appearance. Maize phenology was monitored by means of the recently developed visible atmospherically resistant indices, derived from spectral reflectance data. Visible atmospherically resistant indices provided significant information for crop phenology monitoring as they allowed us to detect: (i) changes due to biomass accumulation, (ii) changes induced by the appearance and development of reproductive organs, and (iii) the onset of senescence, earlier than widely used vegetation indices. Visible atmospherically resistant indices allowed the identification of the timing of phenological transitions that are related to the maize physiological development. They also allowed identification of the onset of the grain-fill period, which is important since maximum yield potential of maize plants depends on optimal environmental conditions during this period.
\end{abstract}

$\mathrm{A}^{\mathrm{c}}$ CCURATE MONITORING of crop development patterns (i.e., phenology and growth) is an important component of farm management since it allows assessing if the most critical stages of growth occur during periods of favorable weather conditions. Phenological monitoring also improves the understanding of crop development and growth processes.

Several dynamic simulation models that compute daily growth and development of a crop, simulating dry matter production of the plants from emergence to maturity and finally presenting an estimate of final yield, have been developed (Sun, 2000). These models often failed when applied in nonoptimal growing conditions (e.g., damaging frost, hail, pests or disease infestation, and/ or drought, among others). Instances of nonoptimal growing conditions, therefore, warranted the use of remote-sensing data to calibrate the models and adjust for possible improvement or decline in crop health/status (Clevers et al., 1994).

Maize phenology is generally divided into vegetative (from emergence to tasseling according to the number

A. Viña, A.A. Gitelson, and D.C. Rundquist, Cent. for Advanced Land Manage. Information Technol., and School of Nat. Resour., Univ. of Nebraska-Lincoln, 113 Nebraska Hall, Lincoln, NE 685880517; G. Keydan and B. Leavitt, Cent. for Advanced Land Manage. Information Technol., Univ. of Nebraska-Lincoln, 113 Nebraska Hall, Lincoln, NE 68588-0517; and J. Schepers, USDA-ARS and Dep. of Agron. and Hortic., 113 Keim Hall, Univ. of Nebraska-Lincoln, Lincoln, NE 68583-0915. Received 8 Oct. 2003. *Corresponding author (avina@calmit.unl.edu).

Published in Agron. J. 96:1139-1147 (2004).

(C) American Society of Agronomy

677 S. Segoe Rd., Madison, WI 53711 USA of fully expanded leaves, $\mathrm{n}$, designated by $\mathrm{V}_{\mathrm{n}}$ ) and reproductive (from silking to physiological maturity according to the degree of kernel development, designated by $R_{n}$ ) stages (Hanway, 1971; Ritchie et al., 1992). Within these stages, several transitions are important in terms of management by producers: (i) crop emergence (date of onset of photosynthetic activity, termed VE), (ii) tasseling (date when maximum leaf area is attained and maize tassels emerge, termed VT), and (iii) initiation of senescence (date at which green leaf area visibly begins to decrease). To maximize yields, the plants need, on a per-stage basis, to optimize the supply of nutrients and to be maintained under favorable environmental conditions (i.e., temperature, solar radiation, soil moisture). Unfavorable conditions occurring between crop emergence and leaf development will limit the size of the leaves and thus the amount of photosynthetic biomass (i.e., size of the factory). Unfavorable conditions at the beginning of the reproductive cycle (between tasseling and anthesis) are likely to impair pollination and reduce the number of fertilized kernels that are destined to be filled. Adverse conditions during the grain-filling period (between anthesis and physiologic maturity) will reduce the size of kernels that can eventually be harvested. It is obviously important to not only be aware of the time of tasseling but also to identify stress-induced abnormalities during the period of rapid leaf expansion (V6 to V14) so that corrective measures can be considered. Detecting the early onset of senescence, possibly brought on by water stress or disease or $\mathrm{N}$ stress before the R2 growth stage, is important because it can have a direct influence on yield.

Recognition that radiation reflected by vegetation in the visible and near-infrared (NIR) regions of the electromagnetic spectrum contains a measure of the amount and condition of photosynthetically active green foliage has led to the development of various mathematical combinations of visible and NIR reflectances intended to isolate the vegetation signal. These are called vegetation indices and are widely used for remote sensing of vegetative canopies (e.g., Rouse et al., 1973; Tucker, 1979; Jackson, 1983). The basic spectral information structure of these indices consists of signals from the foliage component of vegetation canopies mixed with signals, of variable brightness, from background soils, litter, and shadows. Among them, the normalized differ-

Abbreviations: AGDD, accumulated growing degree days; GDD, growing degree days; MERIS, Medium Resolution Imaging Spectrometer; MODIS, Moderate Resolution Imaging Spectrometer; NDVI, normalized difference vegetation index; NIR, near infrared; SFD, scaled first derivative; VARI, visible atmospherically resistant index (or indices). 
ence vegetation index (NDVI; Rouse et al., 1973) has been the most frequently used.

Time series of NDVI have been used at field and regional scales for monitoring crop dynamics and for yield prediction (e.g., Quarmby et al., 1993; Lee et al., 2000). Considerable efforts have also been expended in predicting the start and end of the growing season using NDVI, not only in crops but also in natural ecosystems (e.g., Reed et al., 1994; Kaduk and Heimann, 1996; Moulin et al., 1997; Myneni et al., 1997; White et al., 1997; Schwartz and Reed, 1999; Schwartz et al., 2002; Zhang et al., 2003). Nevertheless, in all these cases, the phenologic state has been based on biomass accumulation (i.e., leaf production) and not by the development and appearance of reproductive organs. Normalized difference vegetation index was found to be insensitive to changes in biomass at moderate-to-high vegetation density (Kanemasu, 1974; Vogelmann et al., 1993; Buschmann and Nagel, 1993; Gitelson et al., 1996, 2002). Alternative indices have been proposed for remote estimation of leaf area index (Gitelson et al., 2003a) and vegetation fraction (Gitelson et al., 2002). For the latter, visible atmospherically resistant indices (VARI) were suggested, which only use channels in the visible region of the electromagnetic spectrum.

The objective of this paper is to remotely evaluate the phenological development of maize in terms of both biomass accumulation and reproductive organ appearance. We intend to demonstrate the feasibility and practicality of incorporating VARI to the study of crop phenology in an intensive maize production system. The synoptic view obtained by remotely sensed imagery, used in combination with these recently developed techniques, might provide a mechanism to establish both timing and synchronicity of crop phenological transitions at the individual field and at regional scales.

\section{MATERIALS AND METHODS \\ Study Area and Crop Cultural Practices}

During the growing seasons of 2001 and 2002, we took advantage of an established research facility, which is part of the Carbon Sequestration Program at the University of Nebraska-Lincoln Agricultural Research and Development Center (UNL-ARDC), funded by the U.S. Department of Energy EPSCoR program. The research facility is located 58 $\mathrm{km}$ northeast of Lincoln, NE, USA. During the 2001 growing season, two large production fields (each 65 ha) irrigated with center-pivot systems and a rainfed field (65 ha) were planted at the beginning of May with maize. For the irrigated fields, a Bt corn borer-resistant hybrid was planted (Pioneer brand '33P67', $114 \mathrm{~d}$ to reproductive maturity) in an east-west row direction at a population of 84000 plants/ha. To meet the requirements for a $20 \%$ non-Bt refuge, the pivot corners of these fields were planted with a non-Bt hybrid (Pioneer brand '33B50', 112 d). Water application was determined based on crop water budget, by using predicted crop water use and daily monitoring of rainfall, irrigation, soil evaporation, and soil moisture, maintaining a minimum soil moisture availability of $50 \%$ within the root depth zone. Soil moisture in the root zone was measured using water content reflectometers (ThetaProbe mL2x, Delta-T Devices, Cambridge, UK). These reflectometers were installed at depths of $10,25,50$, and 100 $\mathrm{cm}$. Liquid fertilizer (urea ammonium nitrate) was used as the $\mathrm{N}$ source. For the dryland field, a Bt hybrid (Pioneer brand '33B51', $113 \mathrm{~d}$ ) was planted in an east-west row direction at a population of 61750 plants/ha. A non-Bt isoline to this hybrid (Pioneer brand 33B50,112 d) was planted on the north and south borders of this field to meet the $20 \%$ non-Bt refuge requirement.

During the 2002 growing season, only one irrigated field was planted with maize. Hybrids and cultural practices remained the same as during the 2001 growing season.

\section{Spectral Reflectance Measurements at Canopy Level}

Spectral reflectance measurements were performed from the beginning of June until the beginning of October (18 measurement campaigns) in 2001 and from the beginning of May until the beginning of October (31 measurement campaigns) in 2002. A dual-fiber system, with two intercalibrated Ocean Optics (Dunedin, FL) USB2000 radiometers mounted on Goliath, an all-terrain sensor platform (Rundquist et al., 2004), was used to collect data in the range 400 to $900 \mathrm{~nm}$ with a spectral resolution of about $1.5 \mathrm{~nm}$. Radiometer no. 1, equipped with a $25^{\circ}$ field-of-view optical fiber, was pointed downward to measure the upwelling radiance of maize $\left(L_{\lambda \text { maize }}\right)$. The position of the radiometer above the canopy was kept constant throughout the growing season (i.e., $\approx 5.4 \mathrm{~m}$ ), yielding a sampling area with a diameter of $\approx 2.4 \mathrm{~m}$. Radiometer no. 2, equipped with an optical fiber and cosine diffuser (yielding a hemispherical field of view), was pointed upward to simultaneously measure incident irradiance $\left(E_{\lambda \text { inc }}\right)$. To match their transfer functions, intercalibration of the radiometers was accomplished by measuring the upwelling radiance $\left(L_{\lambda \text { cal }}\right)$ of a white Spectralon reflectance standard (Labsphere, Inc., North Sutton, NH) simultaneously with incident irradiance $\left(E_{\lambda \text { cal }}\right)$. Percentage reflectance $\left(\rho_{\lambda}\right)$ was computed as:

$$
\rho_{\lambda}=\left(L_{\lambda \text { maize }} / E_{\lambda \text { inc }}\right) \times\left(E_{\lambda \text { cal }} / L_{\lambda \text { cal }}\right) \times 100 \times \rho_{\lambda \text { cal }}
$$

where $\rho_{\lambda \text { cal }}$ is the reflectance of the Spectralon panel linearly interpolated to match the band centers of each radiometer. One critical issue with regard to the dual-fiber approach is that the transfer functions of both radiometers must be identical. We tested our Ocean Optics instruments under laboratory and field conditions and found that over a 4-h period, the coefficient of variation of the ratio of the two transfer functions did not exceed $0.4 \%$.

Six plots were established per field for these measurements, each with six randomly selected sampling points. Data were collected with the sensors configured to take 15 simultaneous upwelling radiance and downwelling irradiance measurements, which were internally averaged and stored as a single data file. Radiometric data were collected close to solar noon (between 1100 and $1400 \mathrm{~h}$ daylight time) when diurnal changes in solar zenith angle are minimal. Measurements took about 3 to $4 \mathrm{~min}$ per plot and about $20 \mathrm{~min}$ per field. The two radiometers were intercalibrated immediately before and immediately after measurements in each field. To mitigate the impact of solar elevation on radiometer intercalibration, the anisotropic reflectance from the calibration target was corrected, under sunny conditions, in accord with Jackson et al. (1992). This correction was not performed under diffuse light conditions, characteristic of cloudy days. To study the effect of tassels on canopy reflectance, canopy spectral readings were obtained in the same area before and after removing all the tassels within the field of view of the spectroradiometer. 


\section{Reflectance Measurements of Leaves and Tassels}

During the 2002 growing season, reflectance spectra of topcollar maize leaves of plants located in the same sampling area used for canopy reflectance measurements were acquired weekly, from the beginning of May until the end of September. A black plastic polyvinyl chloride (PVC) leaf clip, with a 2.3mm-diam. $\left(0.042 \mathrm{~cm}^{2}\right)$ bifurcated fiber optic attached to both a hand-held Ocean Optics USB2000 spectroradiometer and an Ocean Optics LS-1 tungsten halogen light source, was used for these measurements. With the leaf clip, individual leaves are held with a $60^{\circ}$ angle relative to the bifurcated fiber optic. A Spectralon reflectance standard (99\% reflectance) was scanned for each of four leaf samples. The reflectance factor at each wavelength was calculated as a ratio of upwelling leaf radiance to the upwelling radiance of the standard and averaged across 10 separate scans made for each leaf. All scans were corrected for the instrument's dark current.

Total chlorophyll (Chl) content (i.e., chlorophyll $a+b)$ in $\mathrm{mg} / \mathrm{m}^{2}$ was derived from reflectance in the red edge between 700 and $710 \mathrm{~nm}\left(\rho_{\text {Red Edge }}\right)$ and NIR between 750 and $800 \mathrm{~nm}$ $\left(\rho_{\mathrm{NIR}}\right)$ ranges using the equation (Gitelson et al., 2003b):

$$
\mathrm{Chl}=723.04 \times\left[\left(\rho_{\mathrm{NIR}} / \rho_{\text {Red Edge }}\right)-1\right]-10.76
$$

Calibration coefficients for this equation were obtained from analytical chlorophyll extraction (Porra et al., 1989) from 70 maize leaves ranging from yellow to green in color. Spectral reflectance readings of these 70 leaves were obtained concurrently, by the same procedures described earlier. Reflectance spectra of maize tassels were obtained by the same setting used for leaves.

\section{Estimation of Green Vegetation Fraction}

To determine green vegetation fraction (i.e., ratio of green vegetation area to ground area), a total of 36 images per sampling campaign were acquired concurrently with spectral data collection, using a Canon (Tokyo, Japan) Camcorder GL1. The area covered by the imagery was set to be approximately $30 \%$ higher than the area covered by the field of view of the radiometer. Vegetation fraction was retrieved from the images using the excess green technique (Meyer et al., 1998). The result of this technique is an image in which green vegetation pixels are brighter than nongreen vegetation pixels (including residue and soil). A threshold value was established as the breakpoint between vegetation and nonvegetation and used to transform the excess green image into a binary image, by assigning 0 to all of the pixels below the threshold value and 1 to all of the pixels above the threshold. The value of this threshold is variable, depending on illumination conditions. Vegetation fraction is then obtained as a ratio of the number of vegetation pixels to the total number of pixels in the image, expressed in percent. An average value for the green vegetation fraction is then obtained from the 36 images acquired per sampling date.

\section{Spectral Vegetation Indices}

The NDVI (Rouse et al., 1973) and the VARI (Gitelson et al., 2002) were calculated as:

$$
\begin{aligned}
\text { NDVI }= & \left(\rho_{\text {NIR }}-\rho_{\text {red }}\right) /\left(\rho_{\text {NIR }}+\rho_{\text {red }}\right) \\
\operatorname{VARI}_{\text {Green }}= & \left(\rho_{\text {green }}-\rho_{\text {red }}\right) /\left(\rho_{\text {green }}+\rho_{\text {red }}-\rho_{\text {blue }}\right) \\
\text { VARI }_{\text {Red Edge }}= & \left(\rho_{\text {Red Edge }}-1.7 \times \rho_{\text {red }}+0.7 \times \rho_{\text {blue }}\right) / \\
& \left(\rho_{\text {Red Edge }}+2.3 \times \rho_{\text {red }}-1.3 \times \rho_{\text {blue }}\right)
\end{aligned}
$$

where $\rho_{\text {NIR }}, \rho_{\text {Red Edge }}, \rho_{\text {red }}, \rho_{\text {green }}$, and $\rho_{\text {blue }}$ are reflectances in the ranges 840 to 880,700 to 710,620 to 670,545 to 565 , and 460 to $480 \mathrm{~nm}$, respectively, simulating those of the Moderate Resolution Imaging Spectrometer (MODIS) onboard the National Aeronautics and Space Administration Terra satellite and the Medium Resolution Imaging Specrometer (MERIS) onboard the European Space Agency Envisat satellite.

\section{First-Derivative Analysis}

To identify the timing of key phenological transitions, a first-derivative analysis was applied to the temporal profiles of NDVI and VARI. For that, the first derivative of the indices with respect to accumulated growing degree days (AGDD) was calculated ( $d$ Index/dAGDD) and scaled by using the ranges of the indices ( $\Delta$ index) and of AGDD ( $\triangle$ AGDD), calculated as the difference between the maximal and the minimal values. The scaled first derivative (SFD) had the form:

$$
\mathrm{SFD}=(d \text { Index } / d \mathrm{AGDD}) \times(\Delta \mathrm{AGDD} / \Delta \text { Index }) \quad[6]
$$

The scaling was performed to compare directly the magnitudes of SFD calculated for NDVI and VARI. Phenological transitions correspond to the inflection points of the temporal profiles of the vegetation indices, specifically regions of local maxima and minima of SFD. Growing degree days (GDD) were calculated using the equation:

$$
\mathrm{GDD}=\left[\left(T_{\max }+T_{\min }\right) / 2\right]-B
$$

where $T_{\max }$ and $T_{\min }$ represent the daily maximum and minimum temperatures, respectively, and $B$ represents a base temperature value of $10^{\circ} \mathrm{C}$. In this calculation, the following adjustments were made: (i) Temperatures below $10^{\circ} \mathrm{C}$ were set at $10^{\circ} \mathrm{C}$, and (ii) temperatures above $30^{\circ} \mathrm{C}$ were set at $30^{\circ} \mathrm{C}$. This upper limit is normally applied in maize (e.g., Cross and Zuber, 1972; Russelle et al., 1984). The starting date for accumulating this base 10 GDD was 1 May.

Zhang et al. (2003) applied a similar type of analysis to exponential and logistic smoothing temporal functions of NDVI and EVI (enhanced vegetation index) acquired in maize and soybean [Glycine max (L.) Merr.] canopies. In the present case, we did not apply a pre-established smoothing function to allow for the natural variability of the vegetation indices as induced by the different phenological events. This analysis was attempted only for the data acquired during the 2002 growing season since the data set available for this year had a higher temporal sampling frequency than the one in 2001, which allows a better description of changes occurring at high temporal frequencies (i.e., at the scale of days).

\section{RESULTS AND DISCUSSION Green Vegetation Fraction}

In both 2001 and 2002 growing seasons, green vegetation fraction ranged from 0 to $94 \%$ for irrigated fields and from 0 to $89 \%$ for the dryland field (Fig. 1A). Coefficients of variation of these measurements ranged between $1.4 \%$ at peak of greenness (July-August) and $11 \%$ at early stages of development (May-June). Maximum green vegetation fraction remained higher in the irrigated fields than in the dryland field for at least $40 \mathrm{~d}$. In the dryland field, the Bt hybrid showed higher vegetation fraction and delayed leaf senescence compared with the non-Bt hybrid (Fig. 1A). In the 2002 growing season, maize showed a faster rate of senescence than in 2001, reaching green vegetation fraction values of zero in early 

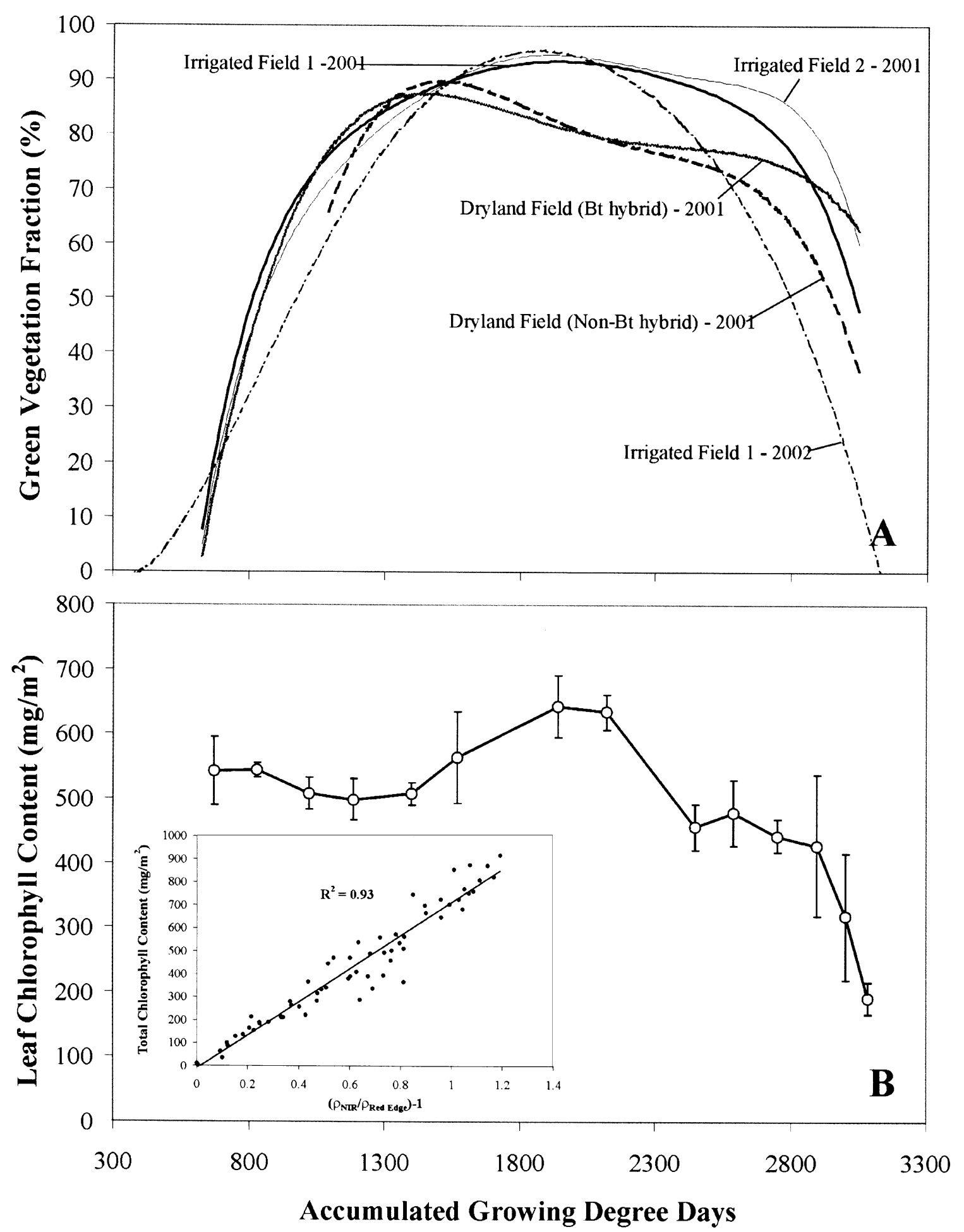

Fig. 1. (A) Temporal profiles of green vegetation fraction of the fields studied, during the 2001 and 2002 growing seasons. (B) Temporal progression of total chlorophyll content in top-collar maize leaves during the growing season of 2002 . Error bars correspond to one standard deviation. Accumulated growing degree days (AGDD) were calculated starting from 1 May. Inset: Relation between total chlorophyll content in $\mathrm{mg} / \mathrm{m}^{2}$ and chlorophyll index of 70 maize leaves $\left\{\mathrm{Chl}=723.04 \times\left[\left(\rho_{\mathrm{NIR}} / \rho_{\text {Red Edge }}\right)-1\right]-10.76 ; r^{2}=0.93 ; p<0.001\right\}$. The coefficients obtained from this equation were used to calculate leaf chlorophyll content of top-collar leaves along the growing season of 2002.

October ( $\approx 3200$ AGDD; Fig. 1A). The 2002 growing season had, on average, $27 \%$ less precipitation and $19 \%$ lower soil moisture than the 2001 growing season (data not shown), which could have induced a faster leaf senescence, even in these irrigated fields.

Figure 1B shows the temporal variability of leaf chloro- phyll in top-collar maize leaves during the 2002 growing season. During the vegetative growth stage, green vegetation fraction variation depends almost entirely on leaf biomass accumulation and not on changes in leaf chlorophyll content. In contrast, as leaves senesce, chlorophyll content is the main factor that affects green vegetation 

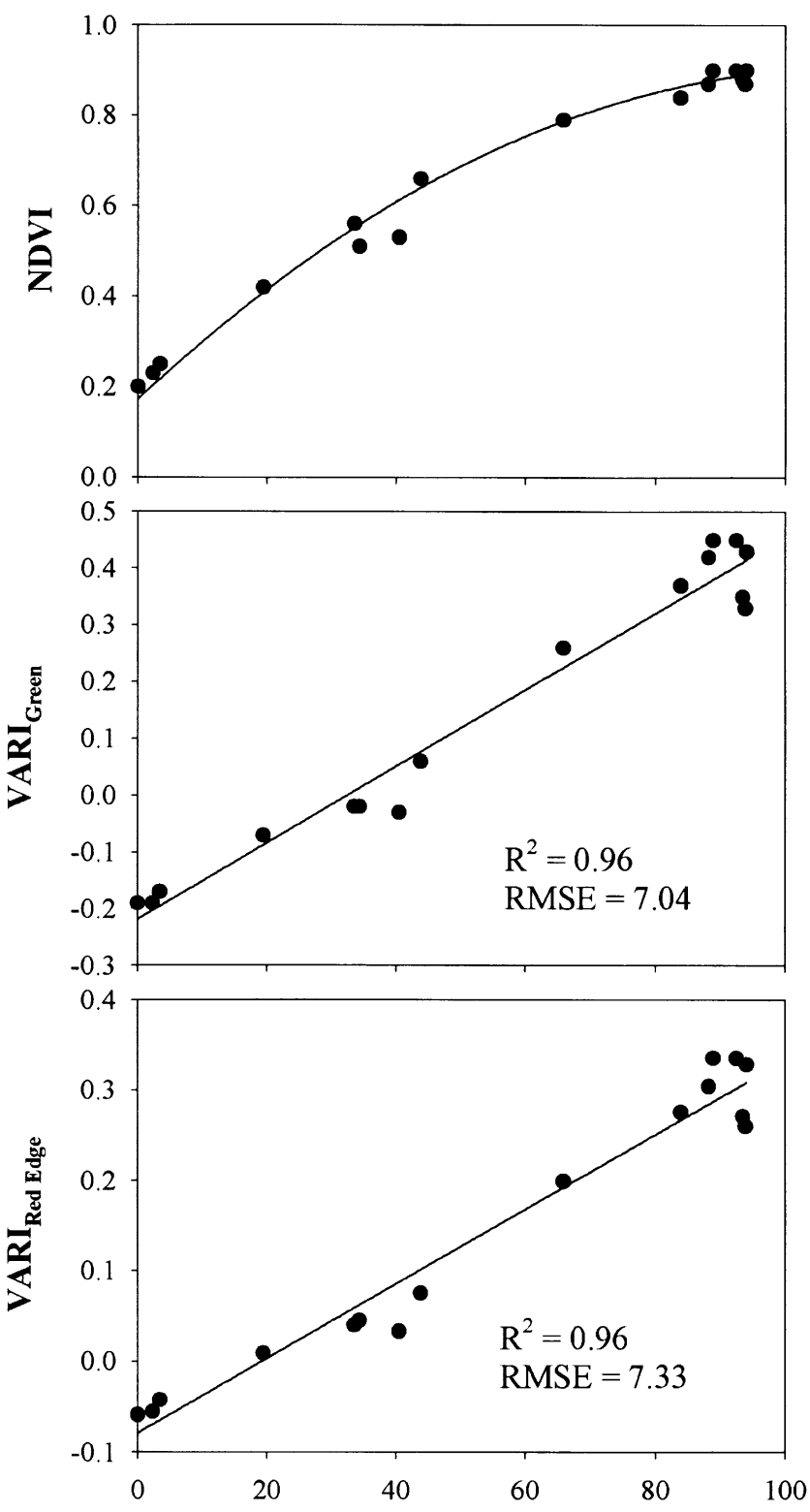

Green Vegetation Fraction (\%)

Fig. 2. Normalized difference vegetation index (NDVI) and visible atmospherically resistant indices (VARI $\mathbf{G r e n}_{\text {reen }}$ and $V A R I_{\text {Red Edge }}$ ) vs. green vegetation fraction of maize during the $\mathbf{2 0 0 2}$ growing season, before silking. Normalized difference vegetation index showed a nonlinear relationship with green vegetation fraction while VARI

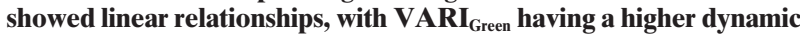
range to allocate green vegetation fraction values than $V A R I_{\text {Red Edge. }}$

fraction. The inset in Fig. 1B shows the relationship $\left(r^{2}=0.93 ; p<0.001\right)$ between total chlorophyll content obtained analytically and the chlorophyll index (Gitelson et al., 2003b). Leaf chlorophyll content showed little variation during the vegetative growth period until just before tasseling (which occurred around the middle of July, AGDD $\approx 1500$ ). Around 1 August (AGDD $\approx$ 1950), leaf chlorophyll content reached its maximum value and remained relatively constant until the middle of August (AGDD $\approx 2200$ ) when it began to decrease.

The relationships between NDVI and VARI vs. green vegetation fraction are shown in Fig. 2. Normalized difference vegetation index showed a nonlinear relation- ship with green vegetation fraction, with high sensitivity to its changes at low to moderate values $(0-60 \%)$ and diminished sensitivity at moderate to high values $(>60 \%)$. In contrast, VARI showed linear relationships with green vegetation fraction, with $\mathrm{VARI}_{\text {Green }}$ having a higher dynamic range to allocate green vegetation fraction values than $\mathrm{VARI}_{\text {Red Edge }}$. Similar results were reported by Gitelson et al. (2002) in both corn and wheat (Triticum aestivum L.) fields.

\section{Temporal Profiles of Vegetation Indices}

In midlatitudes, crop phenology tends to follow a well-defined temporal pattern, indicating a cumulative increase in incoming photosynthetically active radiation as well as an increase in the amount of energy absorbed by the developing canopy. Vegetation indices, obtained from reflectance data acquired during the growing season, can be used to characterize crop phenology by evaluating their variability over time. Figure 3 shows the temporal profiles of NDVI and VARI in the growing seasons of 2001 and 2002. In these figures, time is expressed as AGDD, an indirect measure of the heat and energy available for plant development (Yang et al., 1997). Temporal profiles of NDVI (Fig. 3) show the phenological changes due to biomass accumulation, with a period of early leaf development, a period of maximum canopy expression (where NDVI shows lower sensitivity to changes in green vegetation fraction, see Fig. 2), and a period of senescence. Interannual comparison of the profiles demonstrates that the green-up phase started earlier in 2002 than in 2001, but then it was delayed for a period of $2 \mathrm{wk}$ after which the maize canopy in both years reached maximum greenness at around 10 July (AGDD $\approx 1300$; Fig. 3). Then, greenness only decreased slightly until early September (AGDD $\approx$ 2770) when senescence became conspicuous. The dryland field had similar values of NDVI to those of the irrigated fields during the green-up period but showed lower values after the middle of July $($ AGDD $\approx 1500$ ) and a faster rate of senescence. During senescence, a conspicuous difference between $\mathrm{Bt}$ and non-Bt hybrids was also observed, with the Bt hybrid showing higher values (Fig. 3) and thus a delayed leaf senescence that has been associated with higher yields (e.g., Bänziger et al., 1999).

Temporal profiles of VARI $\mathrm{Vreen}_{\text {and }}$ VARI $\mathrm{RedEdge}_{\text {(Fig. 3) }}$ bring additional information to that obtained using NDVI alone. Visible atmospherically resistant index showed higher sensitivity to changes in the maize green vegetation fraction as it continued to change when NDVI leveled off. As seen through VARI, the canopy reached a maximum green vegetation fraction around the middle of July (AGDD $\approx 1500$ ), followed by a significant decrease in the indices until the middle of August (AGDD $\approx$ 2300) when they reached a steady state and remained almost invariant until the start of senescence in early September $(A G D D \approx 2770)$. The conspicuous decrease in VARI, after the maximum green vegetation fraction was reached at around the middle of July, corresponds with the time of the appearance of the maize tassels.

The spectral reflectance of maize tassels and that of 

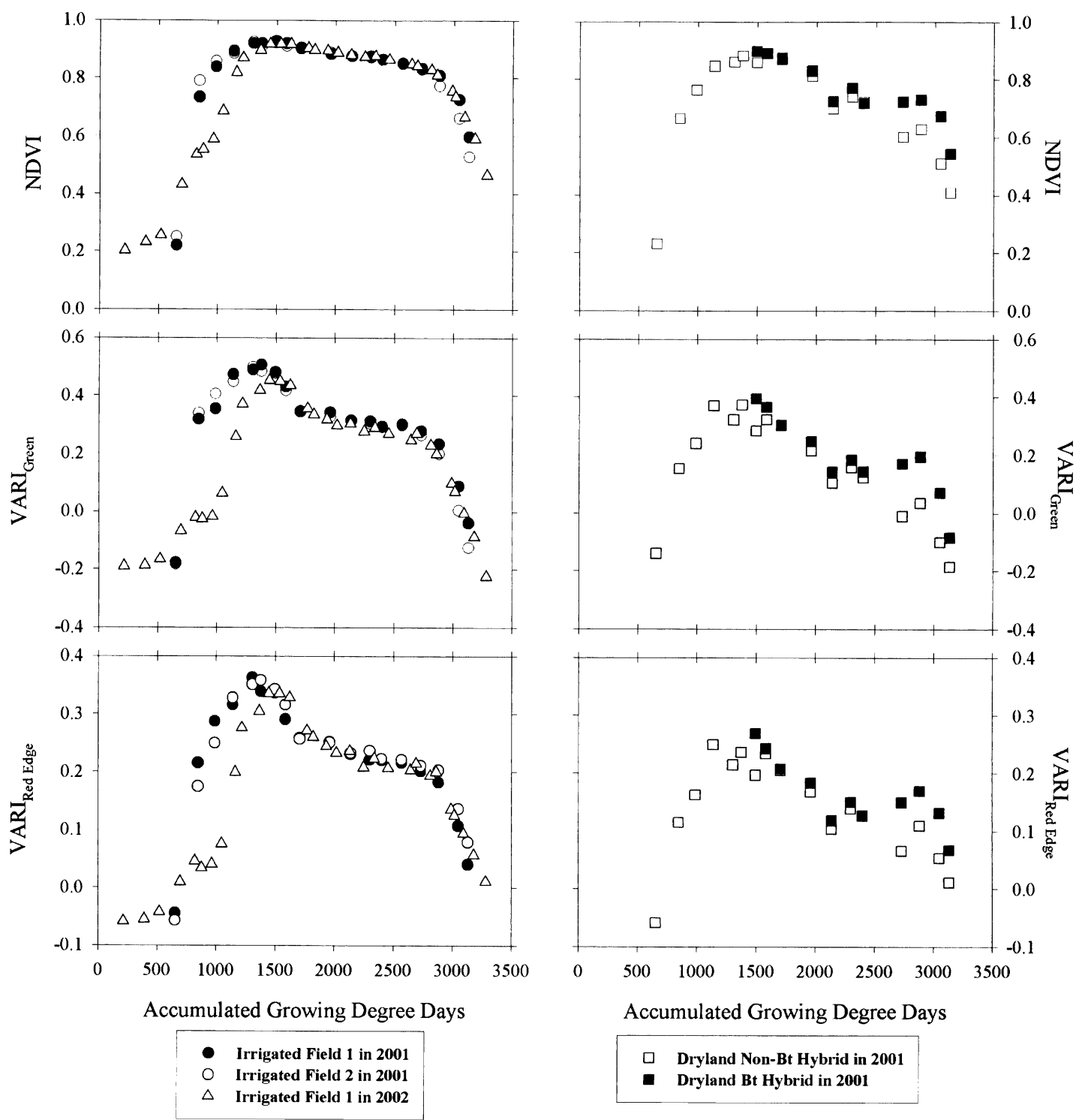

Accumulated Growing Degree Days

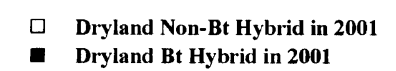

Fig. 3. Temporal profiles of vegetation indices [normalized difference vegetation index (NDVI) and visible atmospherically resistant indices (VARI Green $_{\text {and }}$ VARI $\left.I_{\text {Red Edge }}\right)$ obtained in irrigated (left panel) and dryland (right panel) fields during the 2001 and 2002 growing seasons. Accumulated growing degree days (AGDD) were calculated starting from 1 May.

a healthy green leaf are shown in Fig. 4A. Tassels have higher reflectance at all wavelengths than typical green leaves. Tassels, growing on the tip of each plant, modify the spectral characteristics of the canopy as a whole, reducing the absorption of radiation in the visible region, particularly in the red region (around $670 \mathrm{~nm}$ ) where this reduction is statistically significant $(p<0.1$; Fig. 4B). When canopy green biomass is moderate to high (e.g., between 29 June and 4 September), the tassel appearance does not cause a significant change in NDVI. This is because during this period, NIR reflectance is high (around 50\%) while the red reflectance is much lower (below 3\%); thus, the change in red reflectance with tassel appearance would not affect the ratio due to the fact that both the numerator and denominator in the NDVI calculation remain almost equal (Gitelson, 2004). On the contrary, due to the fact that the magnitude of the green and red-edge reflectance are compara- ble to those of the red, both the numerator and denominator of the VARI are modified significantly by the appearance of tassels. Thus, an increase in the red reflectance due to the tassel appearing would significantly reduce the magnitude of VARI, as seen in Fig. 3.

These results show that the technique is sensitive to the appearance of tassels. Although the results are quantitatively applicable to the hybrids studied, we believe that they are qualitatively applicable to other hybrids. Further analysis is required to test this behavior under different hybrids/environments and if there is a minimum tassel size that is below sensitivity of the radiometric system.

Both NDVI and VARI were sensitive to differences among irrigated and dryland maize fields although NDVI showed a smaller variability among fields when vegetation fraction exceeded 60 to $70 \%$, as opposed to VARI, which showed significantly lower values in the 

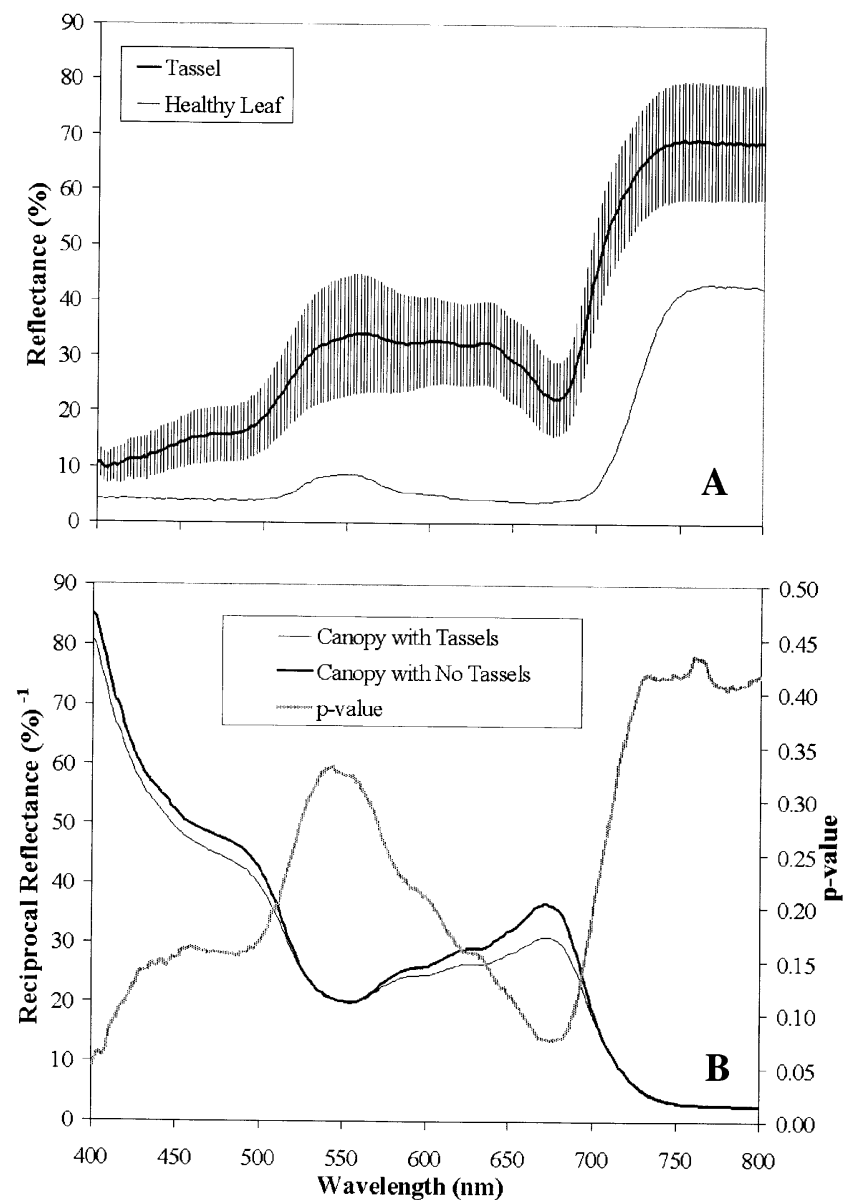

Fig. 4. (A) Spectral reflectance of maize tassels. Error bars correspond to one standard deviation. A typical reflectance spectrum of a healthy maize leaf is also shown for comparison. (B) Effect of the presence of maize tassels in reciprocal reflectance spectra of canopy. Spectral readings were obtained in the same spot before and after removing all the tassels within the field of view of the spectroradiometer. The dotted line represents the probability of a two-sample $t$ test, performed at each wavelength $(n=10)$, to test whether there is a significant difference among reciprocal reflectance spectra of a canopy with tassels and that with the tassels removed. These analyses where performed after checking for variance homogeneity.

dryland field than in the irrigated fields (Fig. 3). Differences between maize hybrids in the dryland field were also conspicuous in both NDVI and VARI, particularly during senescence when the Bt hybrid showed a lower rate of senescence than the non-Bt hybrid (Fig. 3). This suggests that these two types of hybrids have the potential to be differentiated remotely during senescence. In addition, as it was shown in Fig. 1, both NDVI and VARI showed that the year 2002 exhibited a faster rate of senescence, reaching lower values of the indices earlier than in 2001.

\section{Phenological Transitions}

Figure 5 shows the SFD of NDVI and VARI ${ }_{\text {Green }}$ with respect to AGDD for the 2002 growing season. Positive values in SFD correspond to increases in the amount of green vegetation fraction in the canopy while negative values correspond to reductions in the amount of green vegetation fraction. Zero values correspond to no changes.
During the green-up/vegetative stages (before AGDD = 1500 ), the first derivatives of both indices showed mainly positive values, with the exception of two regions of local minima. Zero values occurred for VARI, and minimum values for NDVI, at the beginning of the growing season and at around 800 AGDD. These periods correspond to times in which no changes of green vegetation fraction were achieved, probably due to periods of low incoming radiation, which induce delays in plant development.

Between the beginning of the growing season until AGDD $=1000$, SFD of NDVI shows higher positive values than those of VARI, which means that NDVI is more sensitive to changes in canopy green vegetation fraction than VARI. On the contrary, after AGDD = 1000, VARI SFD values are higher than those of NDVI, expressing the time in which VARI becomes more sensitive to changes in canopy green vegetation fraction than NDVI. When maximum greenness is achieved (i.e., around $\mathrm{AGDD} \approx 1500$ ), SFD of both indices have values close to zero, corresponding to no net accumulation of green vegetation fraction. Immediately after this, there is a time when SFD of both indices is negative, which corresponds to the emergence and development of the tassel. The SFD of VARI shows higher negative values than that of NDVI, which demonstrates that VARI clearly detects the timing of tassel appearance. The emergence of the tassel marks the transition from the vegetation stages to the reproductive stages and also the start of the grain-fill period, a key transition in crop monitoring. Additional changes in SFD of VARI are observed during the reproductive phase, which are not as conspicuous in SFD of NDVI. Such changes might be associated with the different reproductive stages (i.e., silking, blister, milk, dough, and physiological maturity). After this period, senescence starts to be conspicuous, with an increase in negative values of SFD. Visible atmospherically resistant index detected the start of senescence earlier than NDVI (around 110 GDD earlier; Fig. 5), which is in accordance with the higher sensitivity of VARI to leaf chlorophyll content (e.g., Gitelson et al., 2002).

It is important to mention that VARI is sensitive not only to green vegetation fraction, but also to the amount of chlorophyll present in the leaves, and thus different relationships might be found between VARI and green vegetation fraction, one for the green-up period, in which the soil background is progressively covered by leaves, and one for senescence when the leaves progressively lose chlorophyll (Fig. 1B). As such, VARI is suggested for detecting early stages of crop stress. The basis for this suggestion is that one of the effects of stress is the reduction in chlorophyll content, but more research on this subject is needed.

\section{CONCLUSIONS}

Visible atmospherically resistant index showed a linear relationship with green vegetation fraction and higher sensitivity to moderate-to-high green vegetation fraction than NDVI. In addition, using VARI, a pre- 


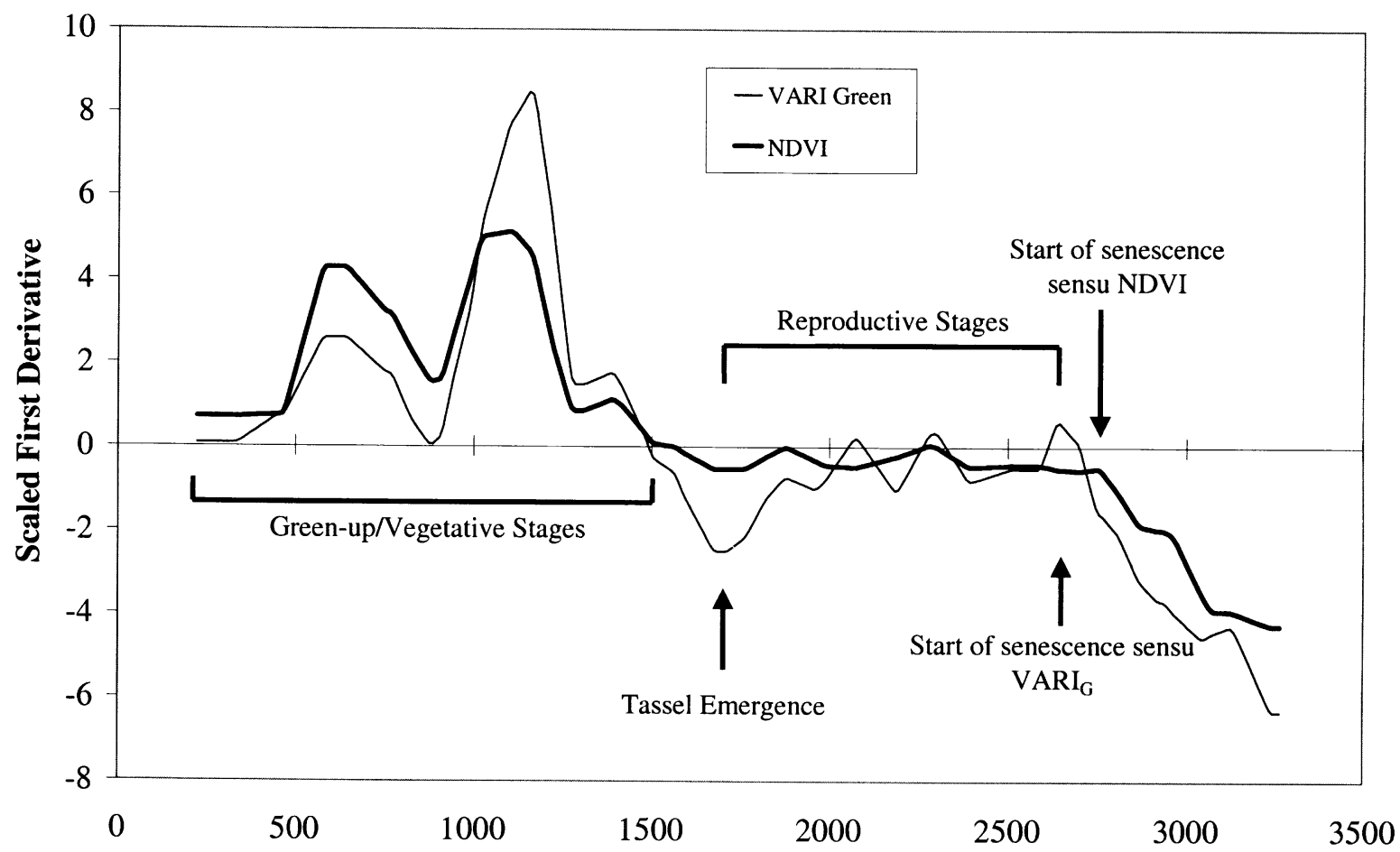

Accumulated Growing Degree Days (AGDD)

Fig. 5. Scaled first derivative (SFD; Eq. [6]) of normalized difference vegetation index (NDVI) and visible atmospherically resistant index (VARI $\left.{ }_{\text {Green }}\right)$ with respect to accumulated growing degree days. Arrows show the dates of critical phenological transitions.

viously undetected physiological transition in the maize phenology was detected. This transition is induced by the emergence of the tassels and also marks the initiation of the grain-fill period, critical for assessing the yield potential of a maize crop. Visible atmospherically resistant index also allowed detection of the onset of senescence earlier than NDVI and thus might be used for early detection of crop stress. As such, the results of this study showed a simple and accurate way of quantifying crop phenology using remotely sensed data.

Although additional validation of the present results is needed to assess their applicability to other maize hybrids and types, our results might be extended to assess crop phenology over broad expanses of agricultural land (e.g., the Corn Belt of the United States) using satellite imagery acquired by sensor systems such as MODIS, MERIS, and SeaWIFS. In addition, although the results have been shown to be successful in maize, monitoring of other row crops might also benefit from these findings.

\section{ACKNOWLEDGMENTS}

This research was supported partially by the U.S. Department of Energy (i) EPSCoR program, Grant no. DE-FG-02-00ER 45827, and (ii) Office of Science (BER), Grant no. DE-FG0300ER62996. We acknowledge the use of facilities and equipment provided by the Carbon Sequestration Program (PIs: Dr. Shashi Verma and Dr. Kenneth Cassman) and the Center for Advanced Land Management Information Technologies (CALMIT), both at the University of Nebraska-Lincoln. We also wish to thank Rick Perk, Jared Burkholder, Giorgio Dall'Olmo, and Jeff Moon for assistance with data collection and three anonymous reviewers for their helpful suggestions. A contribution of the University of Nebraska Agricultural Research Division, Lincoln, NE. Journal Series no. 14328. This research was supported in part by funds provided through the Hatch Act.

\section{REFERENCES}

Bänziger, M., G.O. Edmeades, and H.R. Lafitte. 1999. Selection for drought tolerance increases maize yields across a range of nitrogen levels. Crop Sci. 39:1035-1040.

Buschmann, C., and E. Nagel. 1993. In vivo spectroscopy and internal optics of leaves as basis for remote sensing of vegetation. Int. J. Remote Sens. 14:711-722.

Clevers, J.G.P.W., C. Buker, H.J.C. van Leeuwen, and B.A.M. Bouman. 1994. A framework for monitoring crop growth by combining directional and spectral remote sensing information. Remote Sens. Environ. 50:161-170.

Cross, H.Z., and M.S. Zuber. 1972. Prediction of flowering dates in maize based on different methods of estimating thermal units. Agron. J. 64:351-355.

Gitelson, A.A., J.J. Kaufman, and M.N. Merzlyak. 1996. Use of a green channel in remote sensing of global vegetation from EOSMODIS. Remote Sens. Environ. 58:289-298.

Gitelson, A.A., Y.J. Kaufman, R. Stark, and D. Rundquist. 2002. Novel algorithms for remote estimation of vegetation fraction. Remote Sens. Environ. 80:76-87.

Gitelson, A.A., A. Viña, T.J. Arkebauer, D.C. Rundquist, G. Keydan, and B. Leavitt. 2003a. Remote estimation of leaf area index and green leaf biomass in maize canopies. Geophys. Res. Lett. 30:1248. DOI 10.1029/2002GL016450.

Gitelson, A.A., U. Gritz, and M.N. Merzlyak. 2003b. Relationships between leaf chlorophyll content and spectral reflectance and algorithms for non-destructive chlorophyll assessment in higher plant leaves. J. Plant Physiol. 160:271-282.

Gitelson, A.A. 2004. Wide Dynamic Range Vegetation Index for remote quantification of biophysical characteristics of vegetation. J. Plant Physiol. 161:165-173.

Hanway, J. 1971. How a corn plant develops. Spec. Rep. 48. Iowa State Univ., Ames. 
Jackson, R.D. 1983. Spectral indices in n-space. Remote Sens. Environ. 13:401-429.

Jackson, R.D., T.R. Clarke, and M.S. Moran. 1992. Bidirectional calibration results for 11 Spectralon and $16 \mathrm{BaSO} 4$ reference reflectance panels. Remote Sens. Environ. 40:231-239.

Kaduk, J., and M. Heimann. 1996. A prognostic phenology model for global terrestrial carbon cycle models. Clim. Res. 6:1-19.

Kanemasu, E.T. 1974. Seasonal canopy reflectance patterns of wheat, sorghum, and soybean. Remote Sens. Environ. 3:43-47.

Lee, R., L.A. Kastens, L.P. Price, and E.A. Martinko. 2000. Forecasting corn yield in Iowa using remotely sensed data and vegetation phenology information. Proc. Int. Conf. on Geospatial Information in Agric. and Forestry, 2nd, Lake Buena Vista, FL. 10-12 Jan. 2000. ERIM Int., Ann Arbor, MI.

Meyer, G.E., T. Hindman, and K. Lakshmi. 1998. Machine detection parameters for plant species identification. p. 327-335. In G.E. Meyer and J.A. DeShazer (ed.) Precision agriculture and biological quality. SPIE, Boston.

Moulin, S., L. Kergoat, N. Viovy, and G.G. Dedieu. 1997. Global scale assessment of vegetation phenology using NOAA/AVHRR satellite measurements. J. Clim. 10:1154-1170.

Myneni, R.B., C.D. Keeling, C.J. Tucker, G. Asrar, and R.R. Nemani. 1997. Increased plant growth in the northern high latitudes from 1981-1991. Nature 386:698-702.

Porra, R.J., W.A. Thompson, and P.E. Kriedemann. 1989. Determination of accurate extinction coefficients and simultaneous equations for assaying chlorophylls a and b extracted with four different solvents: Verification of the concentration of chlorophyll standards by atomic absorption spectroscopy. Biochim. Biophys. Acta 975:384 394.

Quarmby, N.A., M. Milnes, T.L. Hindle, and N. Silleos. 1993. The use of multi-temporal NDVI measurements from AVHRR data for crop yield estimation and prediction. Int. J. Remote Sens. 14:199-210.

Reed, B.C., J.F. Brown, D. VanderZee, T.R. Loveland, J.W. Merchant, and D.O. Ohlen. 1994. Variability of land cover phenology in the United States. J. Veg. Sci. 5:703-714.
Ritchie, S.W., J.J. Hanway, and G.O. Benson. 1992. How a corn plant develops. Spec. Rep. 48 (rev.). Iowa State Univ. Coop. Ext. Serv., Ames.

Rouse, J.W., Jr., R.H. Haas, J.A. Schell, and D.W. Deering. 1973. Monitoring the vernal advancement and retrogradation (green wave effect) of natural vegetation. Prog. Rep. RSC 1978-1. Remote Sensing Cent., Texas A\&M Univ., College Station.

Rundquist, D.C., R. Perk, B. Leavitt, G.P. Keydan, and A.A. Gitelson. 2004. Collecting spectral data over cropland vegetation using machine-positioning versus hand-positioning of the sensor. Comput. Electron. Agric. 43:173-178.

Russelle, M.P., W.W. Wilhelm, R.A. Olson, and J.F. Power. 1984. Growth analysis based on degree days. Crop Sci. 24:28-32.

Schwartz, M.D., and B.C. Reed. 1999. Surface phenology and satellite sensor-derived onset of greenness: An initial comparison. Int. J. Remote Sens. 20:3451-3457.

Schwartz, M.D., B.C. Reed, and M.A. White. 2002. Assessing satellitederived start-of-season (SOS) measures in the conterminous USA. Int. J. Climatol. 22:1793-1805.

Sun, J. 2000. Dynamic monitoring and yield estimation of crops by mainly using the remote sensing technique in China. Photogramm. Eng. Remote Sens. 66:645-650.

Tucker, C.J. 1979. Red and photographic infrared linear combinations for monitoring vegetation. Remote Sens. Environ. 8:127-150.

Vogelmann, T.C. 1993. Plant tissue optics. Annu. Rev. Plant Physiol. Plant Mol. Biol. 44:231-251.

White, M.A., P.E. Thornton, and S.W. Running. 1997. A continental phenology model for monitoring vegetation response to interannual climatic variability. Global Biogeochem. Cycles 11:217-234.

Yang, W., L. Yang, and J.W. Merchant. 1997. An assessment of AVHRR/NDVI-ecoclimatological relations in Nebraska, U.S.A. Int. J. Remote Sens. 18:2161-2180.

Zhang, X., M.A. Friedl, C.B. Schaaf, A.H. Strahler, J.C.F. Hodges, F. Gao, B.C. Reed, and A. Huete. 2003. Monitoring vegetation phenology using MODIS. Remote Sens. Environ. 84:471-475. 